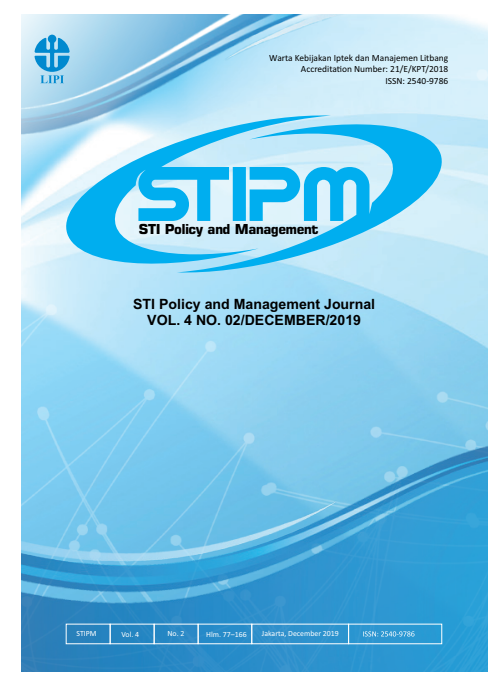

Journal of STI Policy and Management

Publication details, including instructions for authors and subscription information: http://www.stipmjournal.org/

\title{
E-Cigarette as Disruptive Innovation: Forecasting of Conventional Cigarette Substitution in Indonesia
}

\section{Erman Aminullah}

Research Center for STI Policy and Management (RC-STIPM)

Indonesian Institute of Sciences (LIPI)

Version of record first published: 15 December 2019

To cite this article: Aminullah, E. (2019). E-Cigarette as Disruptive Innovation: Forecasting of Conventional Cigarette Substitution in Indonesia. Journal of STI Policy and Management, 4(2), 113-124

To link to this article: http://dx.doi.org/10.14203/STIPM.2019.173

ISSN 2540-9786 (Print); ISSN 2502-5996 (online)

Accreditation Number: 21/E/KPT/2018

Full terms and conditions of use: https://creativecommons.org/licenses/by-nc-sa/4.0/

You are free to:

- Share : copy and redistribute the material in any medium or format

- Adapt : remix, transform, and build upon the material

- The licensor cannot revoke these freedoms as long as you follow the license terms.

Under the following terms: Attribution - You must give appropriate credit, provide a link to the license, and indicate if changes were made. You may do so in any reasonable manner, but not in any way that suggests the licensor endorses you or your use.

$\$$ NonCommercial - You may not use the material for commercial purposes.

(3) ShareAlike - If you remix, transform, or build upon the material, you must distribute your contributions under the same license as the original.

No additional restrictions - You may not apply legal terms or technological measures that legally restrict others from doing anything the license permits.

Notices:

- You do not have to comply with the license for elements of the material in the public domain or where your use is permitted by an applicable exception or limitation.

- No warranties are given. The license may not give you all of the permissions necessary for your intended use. For example, other rights such as publicity, privacy, or moral rights may limit how you use the material.

- If you copy the dataset merely to extract the uncopyrightable data elements would not need permission to do so. However, if you republish the full dataset or using the copyrightable data layers require a permission from Research Center for STIPM, Indonesian Institute of Sciences. 


\title{
JOURNAL OF SCIENCE, TECHNOLOGY AND INNOVATION POLICY AND MANAGEMENT (STIPM JOURNAL), Volume 04, Issue 02, December 2019
}

\author{
FOREWORD by EDITOR-in-CHIEF
}

We are pleased to present the STIPM Journal Vol 4, No. 2, December, 2019. This issue brings together research findings related to science, technology, and innovation policy and management from Japan and Indonesia.

First article was written by Djisman Simanjuntak et al. entitled Exploring the Transition to Eudaimonic Tourism: A Case Study of Bali. This article discusses innovation in tourism focus on the dynamics of tourism grows. As tourism grows, carrying capacity is stretched or even overstretched in some places and industries. A shift toward more eudaimonic tourism is needed, and the innovative elements of eudaimonia include geographical treasure, biodiversity, and local deep culture.

Taeko Suehiro and Kumiko Miyazaki present an article entitled Accumulation of Knowledge by Strategic Public Procurement through Public-Private-Partnership for Service Innovation in Japan. This study focuses on how governments strategically procure public service through Public-Private Partnership (PPP) — or more specifically, Private Finance Initiative (PFI) arrangements.

Erman Aminullah presents E-Cigarette as Disruptive Innovation: Forecasting of Conventional Cigarette Substitution in Indonesia. This article intends to forecast conventional cigarette substitution by e-cigarette in the context of disruptive innovation. E-cigarette as disruptive innovation has been driven by technology innovation to create e-cigarette products for global market. The advancement of e-cigarette technology innovation would continue to create smart and less harmfull e-cigarette as alternative tobacco products in future.

Kumiko Miyazaki, Santiago Ruiz Navas, and Ryusuke Sato present the fourth article entitled Evolutionary Path of Development of AI and Patterns of Knowledge Convergence over the Second and Third AI Boom. AI has been through several booms and we have currently reached the 3rd AI boom which followed the 2nd AI boom centering mainly on expert systems. The current AI boom started around 2013 and $\mathrm{AI}$ is beginning to affect corporate management and operations. AI has been evolving over six decades but it seems that the current boom is different from the previous booms.

The fifth article entitled Predicting Potential Co-Authorship using Random Forest: Case of Scientific Publication in Indonesian Institute of Sciences by Rizka Rahmaida, Asep Saefudin, and Bagus Sartono. Co-authorship network is one of the proxies to evaluate the emerging research collaborations. Co-authorship that happens for the first time among a pair of author plays an important role as the key of success for their co-authorship in the future.

Finally, Hiroki Idota et al., present an article entitled Conducting Product Innovation by Using Social Media among Japanese Firms. This article based on a study that attempts to conduct an empirical 
analysis of how social media use promotes product innovation in Japanese firms by collaboration with consumers based on survey data from Japanese firms using probit analysis. This study finds that collaboration with consumers by using social media is important for innovation, particularly in developing concepts and devising methods of use.

The STIPM Journal is indexed by Google Scholar, ISJD, IPI, DOAJ, BASE, and OCLC World Cat. This make the journal dissemination wider. We would like to thank all the reviewers for their excellent work and the authors who kindly contributed their papers for this issue. We are also indebted to the STIPM Journal editorial office at P2KMI-LIPI and the publishing and production teams at LIPI Press for their assistance in preparation and publication of this issue.

We are expecting that STIPM will always provide a higher scientific platform for the authors and the readers, with a comprehensive overview of the most recent STI Policy and Management research and development at the national, regional dan international level.

Happy New Year 2020 to all of you...

Jakarta, December 2019

Editor-In-Chief 



\section{JOURNAL OF STI POLICY AND MANAGEMENT}

Volume 4, Number 2, December 2019

\section{LIST OF CONTENTS}

Exploring the Transition to Eudaimonic Tourism: A Case Study of Bali

Djisman Simanjuntak, Alvin Desfiandi, Erica Lukas, Isti Setiawati, Nakita Sabrina, and Stanley Makalew

Accumulation of Knowledge by Strategic Public Procurement through Public-Private Partnerships for Service Innovation in Japan

Taeko Suehiro and Kumiko Miyazaki

E-Cigarette as Disruptive Innovation: Forecasting of Conventional Cigarette Substitution in Indonesia

Erman Aminullah

Evolutionary Path of Development of Artificial Intelligent (AI) and Patterns of Knowledge Convergence over the Second and Third AI Booms

Kumiko Miyazaki, Santiago Ruiz Navas, and Ryusuke Sato

Predicting Potential Co-Authorship using Random Forest: Case of Scientific Publications in Indonesian Institute of Sciences

Rizka Rahmaida, Asep Saefuddin, and Bagus Sartono. $143-152$

Conducting Product Innovation by Using Social Media among Japanese Firms

Hiroki Idota, Sheikh Abu Taher, Teruyuki Bunno, and Masatsugu Tsuji $153-166$ 


\title{
in STI POLICY AND MANAGEMENT \\ LIPI Journal homepage: http://www.stipmjournal.org
}

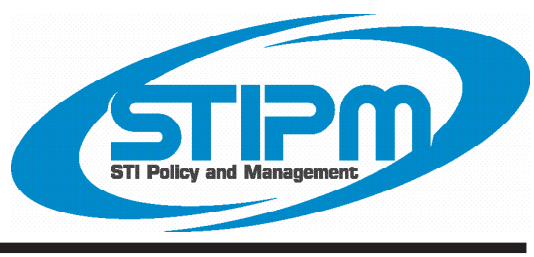

\section{E-Cigarette as Disruptive Innovation: Forecasting of Conventional Cigarette Substitution in Indonesia}

\author{
Erman Aminullah ${ }^{*}$ \\ Research Center for STI Policy and Management (RC-STIPM) \\ The Indonesian Institute of Sciences (LIPI)
}

Jakarta, Indonesia

\begin{tabular}{l}
\hline ARTICLE INFO \\
\hline Article History: \\
Received : 07 August 2019 \\
Revised : 27 November 2019 \\
Accepted : 27 November 2019 \\
Available online : 15 December 2019
\end{tabular}

\begin{abstract}
This paper forecasts conventional cigarette substitution by e-cigarette in the context of disruptive innovation. E-cigarette as disruptive innovation has been driven by technology innovation to create e-cigarette products for global market. The advancement of e-cigarette technology innovation would continue to create smart and less harmfull e-cigarette as alternative for tobacco products in future. The results of the forecasting show that the replacement of conventional cigarette would be in line with the increase of e-cigarette consumption. Future increase of e-cigarette consumption would be influenced by three factors: (i) technology advancement, (ii) excise tax incentives, (iii) and tobacco regulation. The diffusion of e-cigarette products in domestic market has raised the level of public acceptance, despite serious rejections, especially from the health community in Indonesia. The scientific contribution of this paper is a system dynamic model on conventional cigarette substitution by e-cigarette's disruptive innovation. The model is a systemic interaction among cigarette consumption, regulators, and public responses both health community and consumers of e-cigarette in Indonesia.
\end{abstract}

C2019 PAPPIPTEK-LIPI All rights reserved

\section{INTRODUCTION}

Indonesia is the world's fourth most populous country with the fifth largest cigarette market, and one-third of Indonesians smoke tobacco products. Smoking imposes a heavy economic burden in countries, where the tobacco epidemic is most

\footnotetext{
* Corresponding Author.

E-mail: aminullahe@yahoo.com

1 Paper presented in Asian learning, innovation, and co-evolution studies (ASIALICS) Conference, SKKU, Seoul, Korea, July 26-27, 2019.
}

prevalent, like Indonesia. Total medical expenditures in Indonesia due to tobacco attributable diseases was around US\$ 5.15 billions in 2015 (Kosen, Thabrany, Kusumawardani, \& Martini, 2017). The economic burden of smoking in China was US\$ 5 billion in 2000 (Sung, Wang, Jin, Hu, \& Jiang, 2006). In India, the total economic cost of tobacco use was US\$1.7 billion in 2004 (John, Sung, and Max, 2009), and the estimated cost attributable to smoking in Korea was around US\$ 4.5 billion in 1998 (Kang et al., 2000). In order 
to curb economic losses attributable to smoking, countries need effective measures for smoking cessation and tobacco control.

Viewed from a public health perspective, each country has their effective measures for smoking cessation. Medical services play a role in smoking cessation for patients in Indonesia. Medical doctors need to function as practical advisors on how to stop smoking for patients. (Ng-Nawi et al., 2007). Regular advice by a medical doctor to patients and building awareness of adverse health effects of secondhand smoke exposure are effective for smoking cessation in Indonesia (Bam, Aditama, Chiang, Rubaeah, \& Suhaemi, 2015). In Korea, smoke-free environment and the strength of patient self-motivation influence the success of smoking cessation. (Kim \& Cho, 2014). In South Africa. besides the importance of a smoke-free environment campaign, intensifying knowledge dissemination on the dangers of smoking may increase the rate of smoking cessation for patients. (Ayo-Yusuf \& Szymanski, 2010)

In connection with the widespread use of e-cigarette in society, the results of studies on e-cigarette as the substitution for conventional cigarette or as a tool of nicotine replacement therapy (NRT) are inconclusive. A recent study on e-cigarette in the context of smoking cessation argued that: (i) e-cigarette is less toxic than conventional cigarette, and (ii) the increase of e-cigarette smokers correlate with the reduction in conventional smokers. (Ghosh \& Drummond, 2017) The results of a study from Giovenco and Delnevo (2018) concluded that there was a strong relationship between regular use of e-cigarette and the conventional cigarette cessation as well as the avoidance of conventional smoking relapse.

This paper forecasts conventional cigarette substitution by widespread use of e-cigarette products including vape and 'heat not burn tobacco' (HNBT) in Indonesia. Both vape and HNBT are called other tobacco products in Indonesia (Hakim \& Aminullah, 2019). System dynamics modelling was used to explain the future possibilities of consuming e-cigarette as the substitution for conventional cigarettes. Forecasting is set with a basic assumption that the future Indonesian society would become consumers like technology and innovation as in developed countries. Moreover, it would be enforced by the number of young Indonesian population exposed to global life style and who gain better education. Before presenting the resuls of forecasting, the following section described the context of forecasting, namely e-cigarette as a disruptive innovation.

\section{E-CIGARETTE AS DISRUPTIVE INNOVATION}

Disruptive innovation (DI) first introduced by Clayton Christensen, is the process of innovators' success in creating and maintaining sustainable growth (Christensen \& Raynor, 2003). DI is a process by which a product or service takes root initially in simple applications at the bottom of a market and then moves up-market, eventually displacing established competitors. Disruptive innovation leads to relatively rapid and dramatic transformations in manufacturing, marketing, and consumer behaviour (Christensen, \& Raynor, 2003). The clasic examples are photographic film replaced by photographic digital and fixed telephone lines substituted by cellular phone. HNBT as the latest innovation in e-cigarrette was predicted to become disruptive innovation to replace conventional cigarette (Spielman, 2017).

E-cigarette as a disruptive innovation, has challenged three things: (i) disrupt the consumer behaviour of smoking by shifting from burning cigarette into vaping and now moves to HNBT, (ii) transform the tobacco company's production line from production of conventional cigarette to meet the new demand on e-cigarette, and (iii) convey the policy discourse for government or regulator in seeking the future options on tobacco control. (Stimson, Thom, \& Costall, 2014)

The innovation race to create alternative e-cigarette products are underway in multinational cigarette manufacturing companies. Since 2013, it has been predicted that the production of e-cigarette will take over the production of conventional cigarettes in the US by 2021 (Craver, 2013). With the emergence of alternative e-cigarette products, namely HNBT, the conventional cigarette substitution process would occur faster that provious predictions. 
E-cigarette products promise something of a higher value that makes the conventional cigarette obsolete. The emergence of HNBT as the latest product innovation in the tobacco sector is the e-cigarette device, which taste like conventional cigarette, but it does not release strong smell and containing less harmful smoke. Smoking by heating without burning tobacco (nicotine) releases fewer harmful chemicals than conventional cigarette, thereby reducing the health risks for the user. Finally, it will reduce economic losses attributable to smoking. The optimistic scenario of HNBT market share would be $66 \%$ in Japan and 52\% in Korea by 2022 (Spielman, 2017).

The possibility of e-cigarette as a substitution for conventional cigarette depends on the interaction among marketing, consumer regulators, policy makers, business people, and lawyers. Above all these elements, there are two determining factors that make conventional cigarette obsolete, namely: (i) competition between electric and conventional cigarette manufacturers, and (ii). the impact of e-cigarette on improving the public health (reduction in deaths related to combustible cigarette). It is expected that the use of conventional cigarette in US will end in 2064 (Abrams, 2014).

The regulation of e-cigarette determines the success of e-cigarette as disruptive innovation in the global market. E-cigarette not only disrupts the conventional cigarette market but also challenges regulations on tobacco control in each country. The regulation of e-cigarette lags behind the rapid marketing of e-cigarette in the global market. The existence of e-cigarette is still controversial in a large part of health communities, it will result in the delay of regulating e-cigarette and slowing down market penetration (Hasselbalch, 2014).

E-cigarette as disruptive innovation, especially HNBT, comes up with the latest concept of tobacco's harm reduction, which created newly competitive tobacco products as a substitute for conventional cigarettes. The future replacement of conventional cigarette due to the emergence of e-cigarettes is a complex systemic process. It involves various elements of a system, which is modeled in the following section.

\section{MODEL OF COVENTIONAL CIGARETTTE SUBSTITUTION}

Continuous innovation in e-cigarette has been creating HNBT since 2015, which makes a breakthrough product with tobacco vapor rather than smoke; it releases a similar taste to tobacco but with reduced levels of harmful chemicals compared to conventional cigarette smoke (Spielman, 2017). E-cigarette has continued to show. It is scientifically proven as less harmfull and having low health risk product for consumers, despite some controversies (Levy et al., 2018).

E-cigarette's disruptive innovation has emerged supported by scientific evidence on less harmful and low health risk for consumers' diseases, namely non-communicable disease (NCD). Increased scientific evidence of HNBT as less harmful products would increase the possibilities of HNBT as a desirably alternative for tobacco product in the future. In some developed countries, the increase of HNBT consumption has disrupted the market of conventional cigarrettes creating conventional cigarette cessation (Spielman, 2017). E-cigarette's disruptive innovation would advocate the public health discourse that the usage of e-cigarette potentially contributes to conventional cigarette cessation and substitution.

Conventional cigarette cessation induced by e-cigarette consumption is basicallly a dynamic interaction between two sub-system: (i) e-cigarette's disruptive innovation, and (ii) people response to the product. The people responses exist in two forms: (i) government response, in the forms of excise tax and e-cigarette regulation, and (ii) health community response related to tobacco health risk and deseases. The main elements of system are: e-cigarette consumption, conventional cigarette consumption, cigarette cessation, and disruptive policy options in terms of excise tax and regulation relaxation. E-cigarette's disruptive innovation created product legitimacy is assumed as an independent element that affects the entirely interdependent elements inside the system.

The main element of concern is cigarettes cessation, which can mean: (i) quitting conventional cigarette and shifting to e-cigarettes influenced by harm reduction, (ii) temporarily quitting e-cigarette and returning back to con- 
ventional cigarette influenced by natural tobacco vapor, and (iii) quitting conventional smoking as well as e-cigarette for health reasons and NCD. Therefore, smokers will stop smoking driven by two possibilities: (i) health reason, because of smoking experiences harm and damage on health, and; (ii) less harmfull reason, fascinated by harm reduction offered in e-cigarette by shifting from conventional cigarettes or stopping conventional cigarettes.

The causal relationship among inter-related elements are: the more aggressive innovation to create the less harmful of e-cigarette, the higher the legitimacy of e-cigrette in the eyes of consumers. An increase in the legitimacy of e-cigarette leads to an increase in e-cigarette consumption by shifting from conventional cigarette consumption. An increasing in e-cigarette consumption will result in the increase of cigarettes cessation through harm reduction. The dynamics of conventional cigarette substitution by e-cigarette's disruptive innovation is depicted in Figure 1.

The model simulation was applied for forecasting the future events of substituting the conventional cigarette by e-cigarettes and explaining the causal mechanism that takes place behind the substitution. The model was set with past values for period 2000-2015 (index $=100$ in 2000 ) and the values were validated with empirical data of adult smokers prevalence in Indonesia. (Hakim \& Aminullah, 2019). Future values are displayed in graphical trends to denote when the possiblity of conventional cigarette substitution would happen. Forecasting by applying a model simulation was done under optimistic assumption that there would be a rapid increase in e-cigarette consumption for Indonesia's future.

Model simulation with policy interventions was applied by using Powersim software. Simulation results revealed various effects of different interventions on model performances. The effects of interventions were evaluated by observing the future trends and values of main variables namely: e-cigarette consumption, conventional cigarette cessation, conventional cigarette consumption. The interpretation of intervention effects were traced based on causal mechanism inside the system in producing future trends and values of main variables. The forecasting results on conventional cigarette substitution and factors affecting substitution are explained in following section.

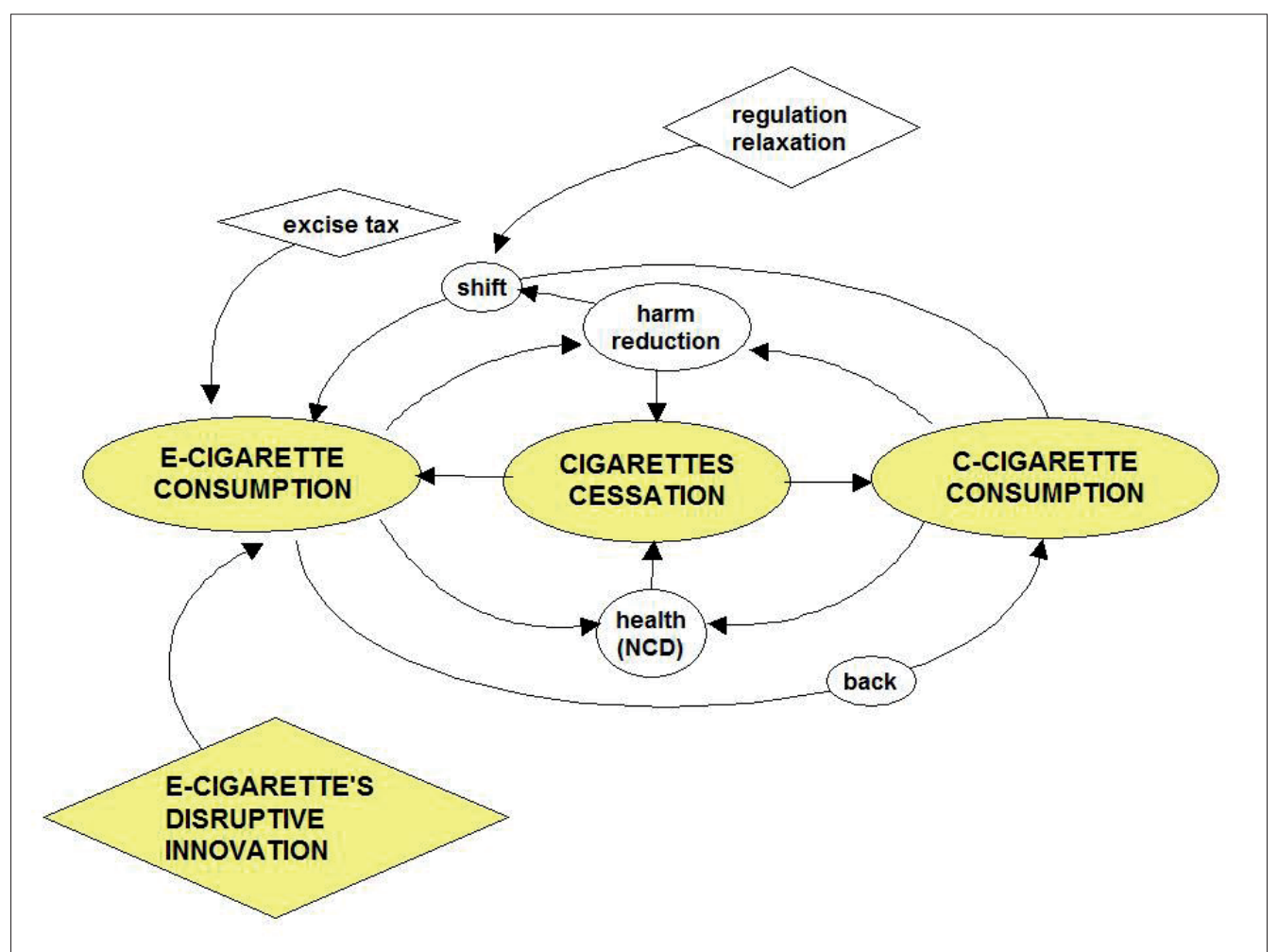

Figure 1. Dynamics of conventional cigarette substitution by e-gicarette's disruptive innovation 


\section{FORECASTING RESULTS}

\section{A. Conventional cigarette Substitution}

The results of system dynamic model simulation showed that starting from 2020, the increase of e-cigarette consumption would be followed by the decreasing trend of conventional cigarette consumption. The consumption of e-cigarette would surpass conventional cigarette consumption within 15-20 years from now. The complete substitution of conventional cigarette by e-cigarette would be unavoidable in mid-2040s; at that time, the very small consumption of conventional cigarette would be a premium or exclusive tobacco product for loyal smokers.

The rapid decrease of conventional cigarette consumption would occur in 2030s and 2040s. The conventional cigarette consumption would fall from its present level of 110 to a minimum level around 5 in mid 2040s. The falling conventional cigarette consumption would be caused by two factors: (i) the increase of e-cigarette consumption as the substitution of conventional cigarette or more people would shift from smoking to vaping and heating device (HNBT) and; (ii) the increase of conventional cigarette cessation caused by other factors aside from e-cigarette consumption, i.e health reasons. In 2045, the conventional cigarette consumption would be at constant level for loyal smokers only and conventional cigarette cessation would be equal to zero (Figure 2).

The rapid increase of conventional cigarette cessation comes from two sources: i) large amount of conventional cigarette cessation would be contributed by increasing in e-cigarette consumption, ii) public health reasons would contribute significantly to e-cigarette cessation. Besides the rapid increase of conventional cigarette cessation, there would be very slow increase in e-cigarette cessation coming from the effect of conventional cigarette cessation, where some people would stop vaping and heating HNBT device because they stopped smoking. The e-cigarette cessation would also be pushed by health reasons, given e-cigarette technology development would becoming scientifically proven as less harmfull poduct but not totally harmless. Model simulation revealed factors affecting conventional cigarette substitution by e-cigarette are explained in the following section.

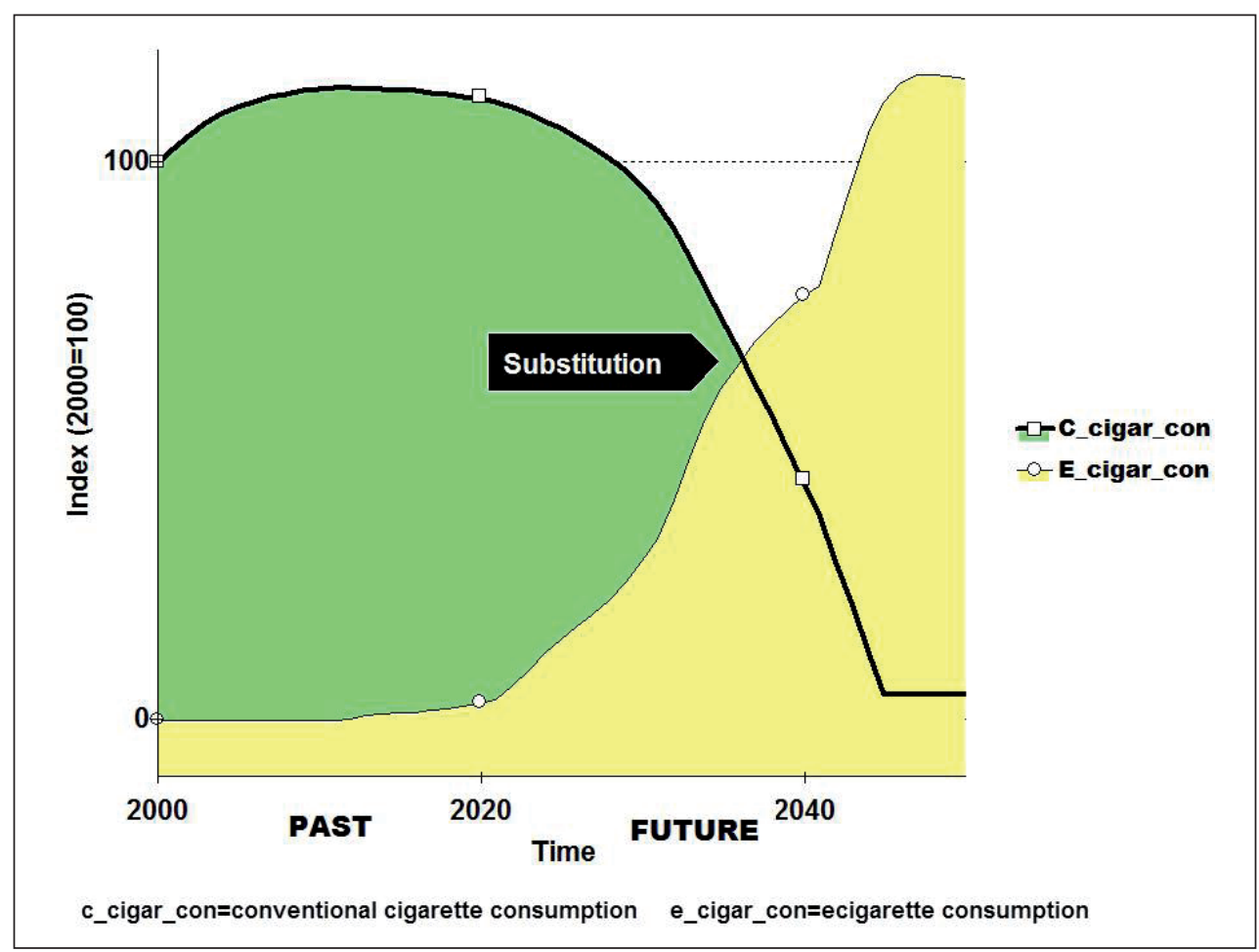

Figure 2. Forecasting of conventional cigarette substitution (Past consumption trend and future possibility) 


\section{B. Factors afffecting substitution}

\section{Technology development}

The nature of technology development follows the path of a technology life cycle; new technology emerges to substitute old technology. The continous innovation in cigarettes based on harm reduction has been occurring from the past until now, and will continue in the future. Innovation progress for creating harm reduction in cigarettte products are driven by continous changes in the user's language about 'safe smoking'. In the 1970s, safe smoking was smoking low-tar cigarette products. In the 2000 s, safe smoking was vaping e-cigarette without tar. Then, since mid-2010, safe smoking has been using HNBT device without tar and odorless. (Fagerström \& Kevin-Bridgman, 2014)

The new product technology penetrates existing market by offering distinctive features not available in earlier technology products. The emergence of HNBT is the latest product innovation in the tobacco market. HNBT is an e-cigarette smoked by a smoker as if it were a conventional cigarette, but it does not contain neither strong smell nor harmful smoke. Smoking by heating without burning tobacco (nicotine) releases fewer harmful chemicals than conventional cigarettes, thereby reducing the health risks for the user. The HNBT is becoming very disruptive to the tobacco sector (Spielman, 2017).

When a new technology product enters the market, initially it is considered as unpromising investment by existing market players. Once the new market player continue to invest in R\&D for creating and proving less harmful product, which becomes more accepted and needed by global customers, the existing dominant player will be disrupted by increasing new product technology legitimation. In the case of e-cigarette technology, the higher the e-cigarette technology legitimacy, the better the people's accepatance of e-cigarette, which leads to an increase in e-cigarette consumption and an decrease in conventional cigarette consumption. Policy simulation showed that continous improvement in e-cigarete technology development has a positive impact of an increase in conventional cigarette cessation (Figure 3).

In real world, technology development is an unstoppable process of technological advancement. E-cigarette's disruptive inovation is an independent element, which continously influenced the system performance. Therefore,

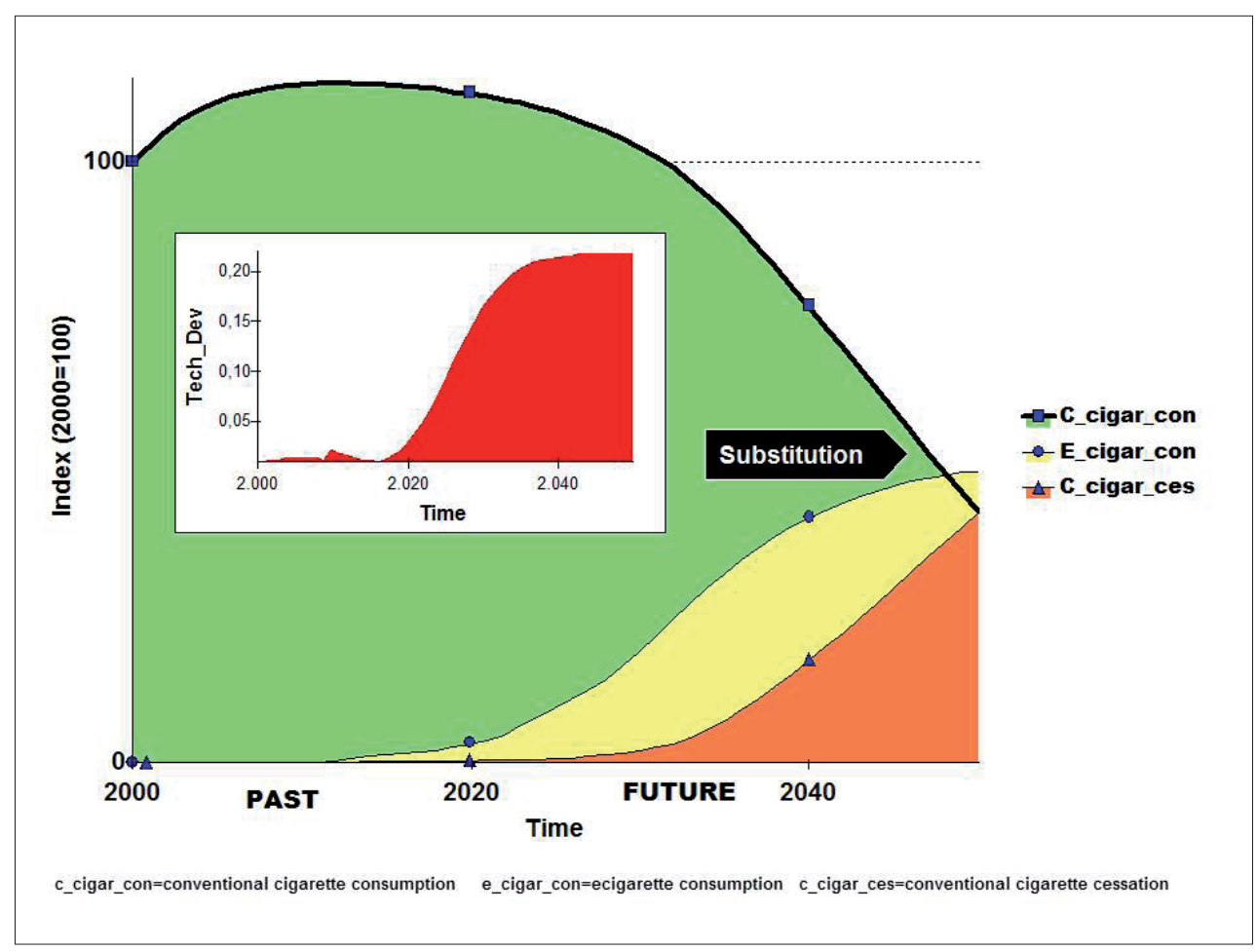

Figure 3. Future possibility of e-cigarette consumption (Technology development effect) 
policy interventions by using excise tax reduction or regulation relaxation, each of which cannot be separated from technology development embedded in e-cigarette's continuous improvement.

\section{Excise tax}

The existence of the tobacco industry is an important source of state revenue from tobacco excise tax. The tobacco industry in Indonesia is now controlled by international tobacco companies, which are main contributors to excise tax for state revenues. Government policy on tobacco control seems to consider the voices of the tobacco industry, as shown by government delay to ratify the Framework Convention on Tobacco Control (FCTC). It is therefore difficult to implement effective legislation to reduce tobacco consumption and exposure to tobacco smoke (Hurt, Ebbert, Achadi, \& Croghan, 2012).

Given current excise tax for the chemical liquid of e-cigarette (57\%) in Indonesia, it is the legal recognition of selling of e-cigarette in domestic market. Excise tax for e-cigarette means authority recognition for product to be distributed legallly in domestic market. With such recognition, e-cigarette company could invest in $\mathrm{R} \& \mathrm{D}$, production facilities and marketing actvity. Company could not only produce for domestic market but also could also expand to global market in future. Excise tax also means the opportunity to increase the production, distribution and consumption of e-cigarette in Indonesia. Furthermore, it will contribute to an increase of government income from excise tax.

Assuming that harm reduction offered by e-cigarette, especially HNBT, will be eligible for tax incentives in the future, the effect of technology development will increase signicantly to both e-cigarette consumption and conventional cigarette cessation. Then, by adding excise tax reduction, the outcomes of intervention will not change significantly. Policy simulation reveals that gradual reduction in excise tax will increase e-cigarette consumption and it has small effect on conventional cigarette cessation. It is because: (i) excise tax reduction directly leads to lowering product prices and increase consumer preferences to consume e-cigarette rather and shifting from conventional cigarette to e-cigarette, and (ii) excise tax reduction will bring the price down and disturb market equilibrium temporarily, then, the market equilibrium will back to stable which is controlled by desired level of e-cigarette consumption (Figure 4).

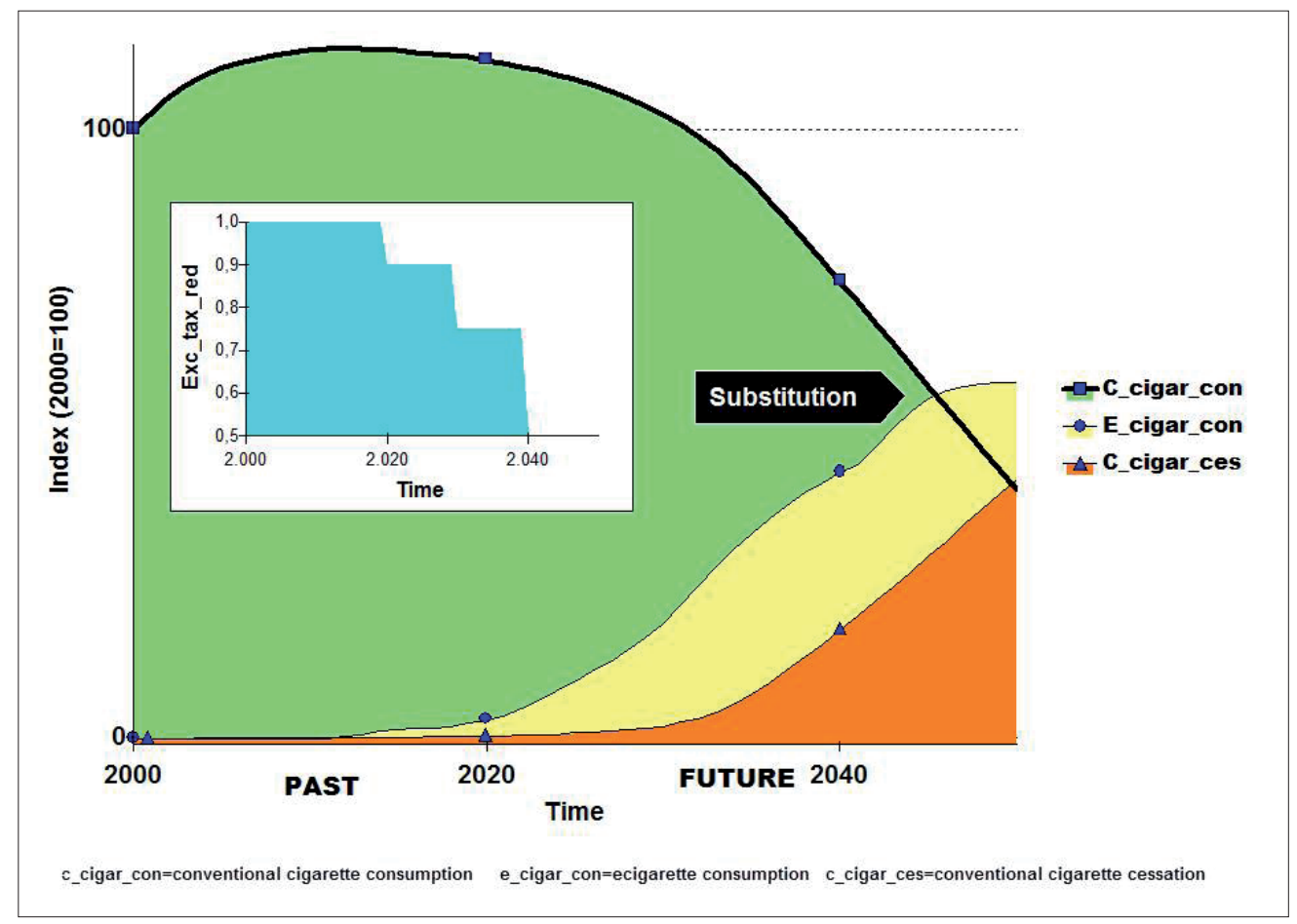

Figure 4. Future possibility of e-cigarette consumption (Excise tax reduction effect) 


\section{Regulation relaxation}

The epidemic caused by tobacco is a man-made disease, and humans can certainly overcome this disease. The success of overcoming the smoking epidemic depends on the actions of government and civil society of a country. The state intervention plays an important role to monitor tobacco use, protect people from tobacco smoke, offer tobacco use, color about the dangers of tobacco, enforce bans on tobacco and promote and raise taxes on tobacco products. (WHO, 2008). Countries have reacted in diverse ways to the introduction of e-cigarette in their markets, ranging from no regulations to a ban on e-cigarette. Up until 2017, 83 countries regulated e-cigarette. Regulatory domains are: i). minimum age for purchase, sale, advertising, promotion and sponsorship, ii). packaging (child safety packaging, health warning labeling, trademark), and iii) product regulation (nicotine volume/concentration, safety/hygiene, ingredients/flavors), reporting/notification, vapefree and tax) (Global Tobacco Control, 2019).

Some publications revealed the scientific evidences on e-cigarette consumption that: (i) vaping had resulted in effective smoking cessation for the majority of participants, (ii) the cancer potencies of e-cigarette were largely under $0.5 \%$ of the risk of smoking, and (iii) e-cigarette deliver lower levels of carcinogens than do conventional cigarette, even though they still expose users to high levels of ultrafine particles and other toxins (Levy, 2017). Assuming harm reduction offered by e-cigarette, especially HNBT, e-cigarettes will be eligible for regulation relaxation in the future. Gradual relaxation of HNBT device regulation, by shifting toward general consumer product regulation, would increase e-cigarette consumption rapidly.

Given the effect, technology development will increase signicantly to both e-cigarette consumption and conventional cigarette cessation. Then, by putting regulation relaxation inside the system structure, the outcomes of government intervention will change drastically. The system structure is significantly changed through the regulation relaxation. The structure is represented by the ratio of conventional cigarette consumption and e-cigarette consumption. The regulatory relaxation will drive e-cigarette consumption that cause a decrease increase in the ratio, as denoted by high increase in e-cigarette consumption and sharp declining consumption of conventional cigarette to the minimum level (Figure 5).

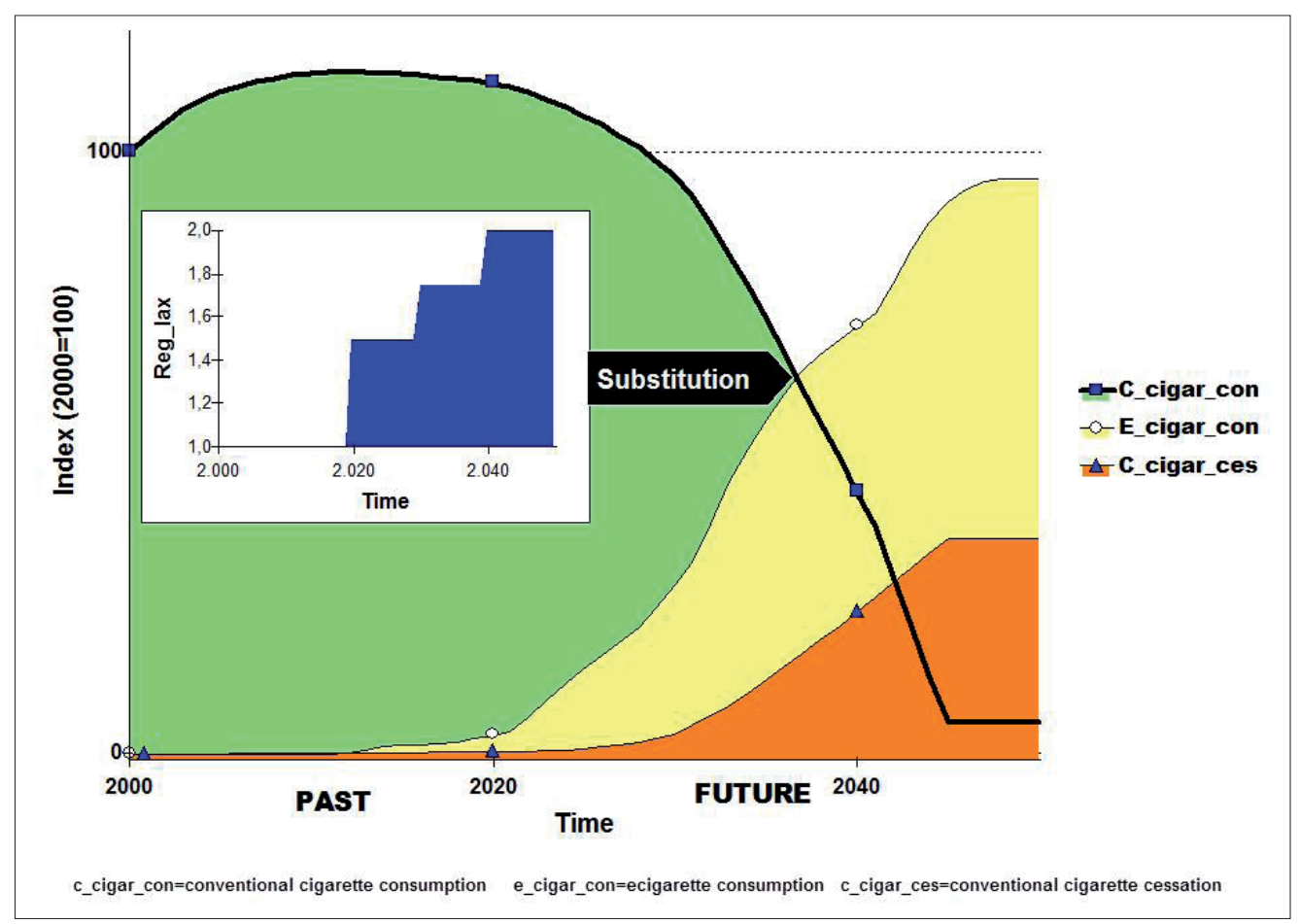

Figure 5. Future possibility of e-cigarette consumption (Regulation relaxation effect) 


\section{Mixed interventions}

This is an intervention in which technology legitimacy is increased with additional intervention of providing excise tax reduction and followed by implementing regulation relaxation. The effect of this intervention would produce a very high increase in e-cigarette consumption to maximum level and a sharp decline in the consumption of conventional cigarette to the minimum level. After reaching the maximum level, e-cigrette consumption would be stable, while very small consumption of conventional cigarette would stay as premium or exclusive tobacco for loyal smokers only (Figure 6).

The process of achieving the maximum level of e-cigarette consumption can be traced from the causal mechanism inside the model structure. There are two factors simultaneously affecting e-cigarette consumption: (i) a change in the parameter of excise tax effects on small increase in e-cigarette consumption, and (ii) a change in the system interaction from regulation relaxation effects on sharp increase in e-cigarette consumption. The more change in the parameter of excise tax, the bigger the effects of change in system interaction leads to create sharp increase in e-cigarette consumption. By changing interaction within the system, the level of e-cigarette consumption would surpass the current level of conventional cigarette in the long run.

\section{DISCUSSION}

The future story of e-cigarette technology development could be followed by the disruptive policy options in the long run, it could be NRT regulation, excise tax reduction and/or regulation relaxation for more safe and less harmfull consumer product. Technology development would open the possibility of e-cigarette as NRT viewed from pharmaceutical perspective. (Barbeau, Burda, \& Siegel, 2013). In view of technology development as a problem solver, policy options on tobacco control with respect to HNBT would develop in future; consequently, ideologically refuse all cigarettes, including e-cigarettes, may not be the best policy (Pang \& Amul, 2018).

An increasing e-cigarette technology development to create alternative tobacco products may lead to higher product legitimacy. It means the availability of more desirable products in market viewed from consumer

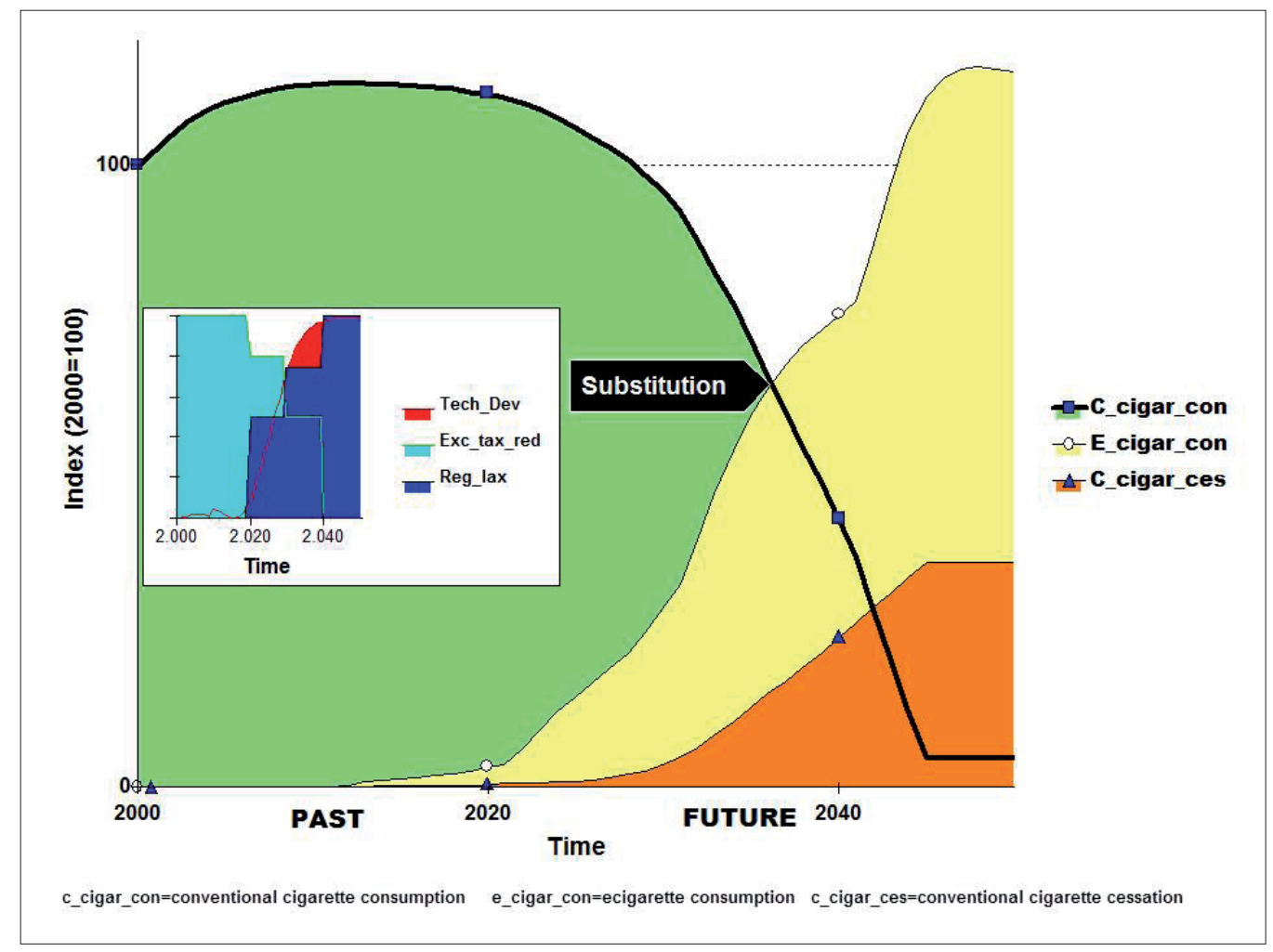

Figure 6. Future possibility of e-cigarette consumption (Combined effects of intervention mix) 
perspective, and relatively more acceptable (or less harmfull) products for people in the view of public health perspective. Although the contradictory perpectives still exist, the process of shifting from conventional cigarette consumption to e-cigarette consumption are finally determined by people reponse to e-cigarette's disruptive innovation. The dynamics interaction are as follows: the more positive people's response, the better e-cigarette's product legitimaticy, where the increase of e-cigarette product legitimaticy again leads to enhance positive people response.

Increase in tobacco excise does not automatically reduce cigarette consumption in Indonesia, due to wide gaps in tax rates between high and low price products. Consumers have the choice to switch to a low price product. In other words, tobacco excise system design contributes to the effect of a tax increase on patterns of consumption (Barber \& Ahsan, 2009). It also a common phenomena in middle and low-income countries, consumers are more responsive to changes in the price of tobacco products than from high-income countries. The increase in the price of tobacco products encourages substitution with cheaper tobacco products. The increase of tax and price is effective for promoting limited cessation on certain tobacco products but not reducing the demand for tobacco products. (Chaloupka, Straif, $\&$ Leon, 2011). In the future, given its relatively high tax and price for 'other tobacco products', HNBT device would become consumer's choice to switch, especially for high income consumers.

In a social policy context, disruptive innovation will be followed by regulating disruptive innovation, where policy disruption will become a future challenge for government or regulator. A policy disruption in e-cigarette would be triggered by the discrete instances of confluence and co-constitution of technological change, governance and markets that drive macro-scale societal development. (Hasselbalch, 2014). The interaction among e-cigarette, regulator, and consumers viewed from system perspective will affect the possible direction of social policy response, especially public health policy. Recent evidence review of e-cigarettes and HNBT was reported by public health commission in England. (McNeill,
Brose, Calder, Bauld, \& Robson, 2018); the U.S. Food and Drug Administration announced it has authorized the marketing of HNBT products in 2019 (FDA, 2019). As already happened in developed countries, due to public health policy discourses, there has been a gradual regulation change and a delay to respond to the e-cigarette technology progress and maypossibly become a challenge for Indonesia as future developed country.

\section{CONCLUSION}

First, the emergence of e-cigarette and its continous innovation by creating HNBT device has disrupted the tobacco-related system elements including: product technology, producers, consumers, public health, and government. The interaction between e-cigarette, regulators, health community, producers and consumers. E-cigarette's disruptive innovation is an independent element that affects the entire interdependent elements inside the system. Viewed from a system perspective, the possibility of conventional cigarette substitution by e-cigarette would occur in the mid 2030s.

Second, the future increase of e- cigarette consumption would be influenced by three factors: (i) technology advancement, continous improvement in e-cigarete technology legitimacy has a positive impact to increase conventional cigarette cessation; (ii) excise tax incentives, tax reduction directly affect by lowering product prices and increase consumer preferences to consume e-cigarette rather and shifting from conventional cigarette to e-cigarette; and (iii) tobacco regulation, relaxation of tobacco regulation drive tobacco's consumer to shift from conventional cigarette to e-cigarette as denoted by a rapid decrease in conventional cigarette consumption.

Third, the diffusion of e-cigarette products in domestic market have raised the level of public acceptance, despite many rejections, especially from the health community in Indonesia. In order to to curb economic losses attributable to smoking, Indonesia needs effective measures for conventional cigarettes cessation. Model simulation concludes that the increase of e-cigarette consumption leads to increasing in conventional 
cigarette cessation, and implies that the public health policy agenda to respond to e-cigarette technology innovation would become a challenge for Indonesia in the future.

Fourth, the scientific contribution of this paper is a system dynamics model on conventional cigarette substitution by e-cigarette's disruptive innovation. The model is a systemic interaction among cigarette consumption, regulators, and public responses both health community and consumers of e-cigarette in Indonesia.

\section{NOTE}

Data source of the paper based on the author's work, which appeared in Hakim and Aminullah (2019). Other tobacco produts technology disruption: forecasting conventinal cigarette replacement with less harmfull tobacco products in Indonesia, Jakarta. (unpublished technical report)

\section{ACKNOWLEDGEMENT}

Author thanks for comments and suggestions of Prof. Lukman Hakim in preparing the early draft.

\section{DATA SHARING STATEMENT}

The model equations and data generated by model simulation in the paper will be made available by Erman Aminullah upon request.

\section{CONFLICT OF INTETEREST}

Author declares no conflict of interest in conducting the study and the contents of paper, which are the sole responsibility of the author.

\section{REFERENCES}

Abrams, D. B. (2014). Promise and peril of e-cigarettes: Can disruptive technology make cigarettes obsolete? The Journal American Medical Association (JAMA), 311(2), 15-16.

Ayo-Yusuf, O. A. \& Szymanski, B. (2010). Factors associated with smoking cessation in South Africa. South African Medical Journal (SAMJ), 100(3), 175-179.

Bam, T. S., Aditama, T. Y., Chiang, C-Y., Rubaeah, R. \& Suhaemi, A. (2015). Smoking cessation and smokefree environments for tuberculosis patients in Indonesia-a cohort study. Biomed Central (BMC) Public Health, 15, 604.
Barbeau, A. M., Burda, J. \& Siegel, M. (2013). Perceived efficacy of e-cigarette versus nicotine replacement therapy among successful e-cigarette users: A qualitative approach. Addiction Science \& Clinical Practice, 8, 5.

Barber, S. \& Ahsan, A. (2009). The tobacco excise system in indonesia: Hindering effective tobacco control for health. Journal of Public Health Policy, 30(2), 208-225.

Christensen, C. M., \& Raynor, M. E. (2003). The innovator's solution: Creating and sustaining successful growth. Boston, MA: Harvard Business Press.

Chaloupka, F. J., Straif, K. \& Leon, M. E. (2011). Effectiveness of tax and price policies in tobacco control. Tobacco Control, 20(3), 235-238

Craver, R. (2013, September 15). Analyst projection: E-cigs will overtake traditional tobacco revenue at Reynolds in 2021. Winston-Salem Journal. Retrieved from https://www. journalnow.com/business/analyst-projectione-cigs-will-overtake-traditional-tobaccorevenue-at/article_948674ca-1ca9-11e3-a0ae0019bb30f31a.html

Fagerström, K.O. \& Kevin-Bridgman, K. (2014). Tobacco harm reduction: The need for new products that can compete with cigarettes. Addictive Behaviors, 39, 507-511.

FDA (2019) FDA permits sale of IQOS Tobacco Heating System through premarket tobacco product application pathway, Retrieved from https://www.fda.gov/news-events/ press-announcements/fda-permits-sale-iqostobacco-heating-system-through-premarkettobacco-product-application-pathway

Ghosh, S. \& Drummond, M. B. (2017). Electronic cigarettes as smoking cessation tool: Are we there? Current Opinion In Pulmonary Medicine, 23(2), 111-116.

Giovenco, D. P. \& Delnevo, C. D. (2018). Prevalence of population smoking cessation by electronic cigarette use status in a national sample of recent smokers. Addictive Behaviors, 76, 129-134

Global Tobacco Control (2019). Country laws regulating e-cigarettes: Policy domains. Retrieved from https://globaltobaccocontrol. org/e-cigarette/policy-domains

Hakim, L. \& Aminullah, E. (2019). Other tobacco produts technology disruption: Forecasting conventional cigarette replacement with less harmfull tobacco products in Indonesia, Jakarta. (unpublished technical report). 
Hasselbalch, J. (2014). Regulating disruptive innovations: The policy disruption of electronic cigarettes. Paper presented at Global Reordering: Towards the Next Generation of Scholarship Conference. Global Reordering- Evolution through Eropean Network (GR:EEN), Brussels, November 18-20, 2014.

Hurt, R. D., Ebbert, J. O., Achadi, A. \& Croghan, I. T. (2012). Roadmap to a tobacco epidemic: Transnational tobacco companies invade Indonesia. Tobacco Control, 21(3), 306-312.

John, R. M., Sung, H-Y. \& Max, W. (2009). Economic cost of tobacco use in India, 2004. Tobacco Control, 18(2), 138-143.

Kang, H. Y., Kim, H. J., Park, T. K., Jee, S. H., Nam, C. M. \& Park, H.W. (2003). Economic burden of smoking in Korea. Tobacco Control, 12(1), $37-44$

Kim, Y., \& Cho,W-K. (2014). Factors associated with successful smoking cessation in korean adult males: Findings from a national survey. Iranian J Publ Health, 43(11), 1486-1496.

Kosen, S., Thabrany. H., Kusumawardani, N., \& Martini, S. (2017). Health and economic costs of tobacco in Indonesia: Review evidence series. Jakarta: Lembaga Penerbit Balitbangkes.

Levy, D. T., Borland, R., Lindblom, E. N., Goniewicz, M. L., Meza, R., Holford, T. R., Yuan, Z., Luo, Y., O'Connor, R. J., Niaura, R. \& Abrams, D. B. (2017). Potential deaths averted in USA by replacing cigarettes with e-cigarettes. Tobacco Control, 053759, 1-8

McNeill, A., Brose, L. S., Calder, R., Bauld, L. \& Robson, D. (2018). Evidence review of e-cigarettes and heated tobacco products 2018: Report commission by public health England. London: PHE Publication.
Ng-Nawi, Prabandari, Y. S., Padmawati, R. S., Okah, F., Keith-Haddock, C., Nichter, M., Nichter, M., Muramoto, M., Poston, W. S. C., Pyle, S. A., Mahardinata, N. \& Lando, H. A. (2007). Physician assessment of patient smoking in Indonesia: A public health priority. Tobacco Control, 16(3), 190-196.

Pang, T. \& Amul, G. (2018, June 9). Why a ban on e-cigarettes may not be the best policy. Strait Times.

Sung, H-Y., Wang, L., Jin, S., Hu, T-W. \& Jiang, J. (2006). Economic burden of smoking in China, 2000. Tobacco Control, Supplement 1: Building Tobacco Control Research around the World, The Fogarty International Center's Tobacco Research and Capacity Building Initiative, Vol 15, i5-i11

Spielman, A. (2017). Heat not burn tobacco lower risk cigarettes. In K. Boyle (Ed.), Disruptive innovations $V$ : Ten more things to stop and think about (pp. 27-31). Retrieved from https:// www.citibank.com/commercialbank/insights/ assets/docs/Disruptive_Innovations_V.pdf

Stimson, G. V., Thom, B. \& Costall, P. (2014). Disruptive innovations: The rise of the electronic cigarette. International Journal of Drug Policy, $25,653-655$.

WHO (2008). The World Health Organization on the global tobacco epidemic. Population and Development Review, 34(1), 188-194. 